\title{
TELENOVELA: UM INSTRUMENTO NO PROCESSO PEDAGÓGICO
}

\section{The soap opera: an instrument in the educational process A telenovela: un instrumento en el proceso pedagógico}

\author{
Luís Fernando Ferreira de Araújo ${ }^{1}$
}

\begin{abstract}
RESUMO
A telenovela embora não seja ainda unanimidade aos olhos e ao gosto do público brasileiro, tornou-se ao longo das três últimas décadas, um marco na história da televisão e da cultura de nosso país. De tão inserida que está em nosso contexto sociocultural, impossível não ser vista hoje como um referencial da arte de representar no Brasil. Nosso objetivo neste artigo é refletir sobre a constituição da telenovela como espaço de diálogo no processo educacional, colocando a telenovela como discussão pedagógica no dia a dia da nossa sociedade.
\end{abstract}

Palavras-chave: Telenovela; cultural; educacional; sociedade; discussão; Pedagogia.

\begin{abstract}
Although soap opera is not yet unanimous in the eyes and taste of the Brazilian public, it has become, over the last three decades, a milestone in the history of television and culture of our country. So that is included in our sociocultural context, impossible not to be seen today as a benchmark of the art of representing in Brazil. Our goal here is to reflect on the formation of a soap opera as space for dialogue in the educational process, putting it as pedagogical discussion in the day-to-day life of our society.
\end{abstract}

Keywords: Soap operas; cultural; educational; society; discussion; Pedagogy.

\section{RESUMEN}

La telenovela, sin embargo no todavía es unanimidad a los ojos y al gusto del público brasileño, se convirtió a través de las ultimas tres décadas, un marco en la historia de la televisión y de la cultura de nuestro país. Es imposible no ser visto hoy como referencial del arte de representar en Brasil de tan involucrado que está en un contexto sociocultural. Nuestro objetivo en este artículo es reflejar sobre la constitución de la telenovela como espacio de dialogo en el proceso educacional, poniéndola como discusión pedagógica en el día a día de nuestra sociedad.

Palabras-clave: Telenovela; cultural; educacional; sociedad; discusión; Pedagogía.

\section{Uma breve história sobre telenovela}

A trajetória da telenovela no Brasil foi se desenvolvendo, progressivamente, em todas as dimensões das imagens preto e branco, até as mais sofisticadas técnicas de fotografias, montagens, cores, sons, gravações e muitos outros recursos que os avanços da tecnologia colocaram na linha do tempo de nosso século.

As primeiras telenovelas, no Brasil, tinham como estrutura o melodrama, ou seja, suas tramas eram carregadas de histórias com assuntos sentimentais. Caracterizaramse pela importação e adaptação de tramas melodramáticas latino-americanas. Nos anos 50 ,

\footnotetext{
1 Mestre em Ciências da Comunicação e Educação, Cultura e História da Arte. Licenciado em Letras. Há 22 anos no ensino superior. Doutorando em Educação, Arte e História da Cultura.
} 
a telenovela foi marcada pela exibição ao vivo, pois ainda não havia videoteipe. Sua duração era curta, em torno de quatro meses no ar. Em 1951, a TV Tupi de São Paulo estreia a primeira telenovela: Sua vida me pertence, escrita e dirigida por Walter Foster, o qual interpretou o papel de herói. A atriz Vida Alves protagonizou a heroína. Com 20 capítulos, a telenovela era apresentada duas vezes por semana, às terças e quintas-feiras, com duração de 20 minutos.

Com a introdução do videoteipe, em 1961, viabilizou-se a telenovela diária, mas sua utilização foi limitada. Somente a partir de 1963, em São Paulo, a primeira telenovela diária gravada em videoteipe foi 2.5499 Ocupado, transmitida pela TV Excelsior, adaptada por Dulce Santucci, baseada no original de Alberto Migré. No elenco: Glória Menezes, Tarcísio Meira, Lolita Rodrigues - Glória Menezes era uma presidiária que trabalhava como telefonista do presídio. Tarcísio se apaixona por ela por meio do único contato: a voz, sem saber sua real condição. Foi exibida no horário das 19 horas, em meados de julho a setembro de 1963, sem muito sucesso, mas seu registro tem grande valor histórico.

A telenovela diária se tornou popular em 1965, com O Direito de Nascer, do cubano Félix Caignet, adaptada por Teixeira Filho e Talma de Oliveira, com direção de Lima Duarte e José Parisi. Transmitida pela TV Tupi, no horário das 21 horas, obteve uma expressiva audiência. Durante oito meses, encantou o telespectador de São Paulo e do Rio de Janeiro com a história de Maria Helena (Nathália Thimberg), mãe solteira na sociedade moralista de Cuba do início do século. Seu filho é ameaçado pelo pai tirano, Dom Rafael (Elísio Albuquerque), que não aceita o neto bastardo. Dolores (Isaura Bruno), empregada da família, foge levando a criança. Com outro nome e em outra cidade, ela cria e educa Albertinho (Hamilton Fernandes) que se forma em medicina. O neto bastardo salva seu avô Dom Rafael e acaba se casando com Isabel
Cristina (Guy Loup). Essa telenovela foi um marco na evolução da telenovela no Brasil.

Depois de O Direito de Nascer, o gênero telenovela se afirmou, afastando-se do melodramático. A primeira telenovela a romper com este gênero foi Beto Rockfeller, de Bráulio Pedroso, com direção de Lima Duarte, que foi ao ar pela TV Tupi às 20 horas, no período de 4 de novembro de 1968 a 30 de novembro de 1969. No elenco: Luís Gustavo, Irene Ravache, Bete Mendes e Plínio Marcos. Essa telenovela incorporou a realidade como cenário e pano de fundo. Em sua trama, havia a situação do dia a dia, próximo da realidade conhecida pelo telespectador, o uso de uma linguagem coloquial, personagens que não eram completamente bons e nem maus e temas voltados para a ascensão social e a malandragem. A partir de Beto Rockfeller, os autores passaram a inserir, nas tramas, referências mais próximas da realidade brasileira, a saber:

- Os problemas do homem do campo e do interior foram abordados nas telenovelas Renascer, Rei do Gado e Cabocla (exibidas pela Rede Globo) e Pantanal (exibida pela Rede Manchete). Todas do autor Benedito Ruy Barbosa.

- O homossexualismo foi abordado de maneira suave nas telenovelas A Próxima Vítima, de Silvio de Abreu, Senhora do Destino, de Aguinaldo Silva, Desejo de Mulher, de Euclydes Marinho e América, de Glória Perez, todas exibidas pela Rede Globo.

- O preconceito racial foi inserido $e$ explorado na trama da telenovela A Próxima Vítima, de Silvio de Abreu.

- O sexo passou a ocupar espaço, com plena liberdade, no horário das 19 horas, nas telenovelas Quatro por Quatro, Uga Uga e Vira Lata, de Carlos Lombardi, exibidas pela Rede Globo.

- $\mathrm{O}$ amor entre pessoas de classes sociais diferentes é frequente nas tramas das telenovelas Belíssima, de Silvio de Abreu, e 
Alma Gêmea, de Walcyr Carrasco, exibidas pela Rede Globo.

A telenovela se desenrola em uma pluralidade dramática, isto é, várias células dramáticas, ligadas entre si. Cada célula tem seu próprio conflito, que, no decorrer da história, o autor vai resolvendo, dentro de uma sucessividade de ações. Essa sucessividade se desdobra em uma liberdade contínua e também na organização dos plots.

Para Doc Comparato (1983, p. 82),

plot é o dorso dramático da história, as ações organizadas em conexão, de modo que se suprimirmos ou deslocarmos qualquer uma delas alterará o todo. Implica a ideia de causa e efeito, referese ao encadeamento dos acontecimentos segundo uma ordem desejada pelo autor. Uma cadeia de acontecimentos.

Ainda, segundo Doc Comparato (1983, p. 89), em sua obra Roteiro para cinema e televisão, os mais usuais plots na ficção televisiva são:

- Plot de Amor - um casal que se ama é separado por alguma razão, volta a se encontrar e tudo acaba bem.

- Plot de Sucesso - histórias de um homem que ambiciona o sucesso, com final feliz ou infeliz, de acordo com o gosto do autor.

- Plot de Triângulo - é o caso típico do triângulo amoroso.

- Plot de Volta - filho pródigo volta à casa paterna, marido que volta da viagem, etc.

- Plot de Vingança - um crime (ou injustiça) foi cometido e o herói faz justiça pelas próprias mãos ou vai à busca da verdade.

- Plot de Família - mostra a relação entre famílias ou grupos que de alguma forma estão ligados.
- Plot de Sacrifício - um herói que se sacrifica por alguém ou por uma causa.

- Plot de Cinderela-éa metamorfose de um personagem de acordo com os padrões sociais vigentes.

- Plot de Conversão - converter um bandido em herói, uma sociedade injusta em justa, etc.

As telenovelas nunca contêm apenas um desses plots. Sendo histórias de multiplot, tratam sempre de três, quatro ou de todos ao mesmo tempo.

A linguagem da telenovela é simples, possibilitando ao telespectador acompanhá-la sem maior esforço de entendimento. O ritmo é acelerado, baseia-se na ação, por isso é uma narrativa de ação. Em decorrência da pluralidade dramática, a telenovela tem um número ilimitado de personagens.

O sucesso da telenovela em relação ao telespectador deve-se à proximidade entre a realidade e a ficção. A trama da novela de televisão envolve quem a assiste, em um processo de relação íntima entre as situações vividas pelos personagens e o real, ao mesmo tempo, que trabalha na mente do telespectador sonhos e desejos. A construção do personagem dentro da teledramaturgia é elaborada por hábitos rotineiros do dia a dia. Ao ver essa situação sendo vivenciada e representada pelo personagem, o telespectador cria um elo de intimidade e integra a fantasia em sua vida durante a exibição da telenovela.

A telenovela é muito mais que um produto de consumo, faz parte do espaço social e cultural das pessoas. Sua trama envolve o público, $e$, muitas vezes, em um nível de audiência que causa uma mobilização por parte da população do país. Lembramos o sucesso da telenovela Vale Tudo de Gilberto Braga, exibida pela Rede Globo em 1988, em que ocorreram apostas pelo Brasil a fora, sobre quem seria o assassino da megera Odete Roithman (Beatriz Segal). 
A telenovela tem uma relação de contato com o telespectador, por meio da imagem, provocando e, ao mesmo tempo, seduzindo-o com lugares maravilhosos. O cenário externo da telenovela tornou-se um laço para o turismo e tem a função de estratégia, de impressão. Por exemplo, a região do Pantanal, vista na telenovela Pantanal, a região do Araguaia em O Rei do Gado,.e o litoral do Ceará, em Tropicaliente (Walter Negrão, Rede Globo 1994), desenvolvendo no telespectador o imaginário e transportando-o a um mundo totalmente diferente do seu. Assim, o autor usa o cenário como forma de merchandising e, ao mesmo tempo, para divulgação e/ou insinuação ao turismo dentro do Brasil, e também, um cartão-postal de peso no exterior.

Com o surgimento da Rede Globo, em 1965, a telenovela se revelou um grande sucesso, devido aos recursos sofisticados e à produção cuidadosa que fizeram do gênero um dos fenômenos singulares da televisão brasileira. A Globo dominou o mercado e hoje é líder de audiência. Suas telenovelas conquistaram, com o passar do tempo, uma forma de apresentação ainda não substituível.

As primeiras telenovelas produzidas pela Rede Globo ficaram a cargo da cubana Glória Magadan. São elas: O Sheik de Agadir em 1966, A Rainha Louca em 1967, Eu Compro Essa Mulher em 1966 e A Sombra de Rebeca em 1967, com enredos melodramáticos, ambientados em terras estrangeiras, com personagens maniqueístas em meio a intrigas românticas, no estilo capa e espada. Com a saída de Glória Magadan, a Globo abre espaço para a entrada de autores como Janete Clair, Dias Gomes, Walter G. Durst, Lauro César Muniz, Gilberto Braga, Benedito Ruy Barbosa e Walter Negrão. Esses autores trouxeram novas temáticas, acabaram com os enredos melodramáticos e introduziram temas voltados para a realidade brasileira.

Em 1995, a Globo construiu um estúdio e uma cidade cenográfica para suas produções em Jacarepaguá, no Rio de Janeiro. Também adquiriu vários aparelhos de última geração, para que suas telenovelas fossem produzidas com uma dimensão cinematográfica, semelhante às realizações hollywoodianas. Transformou-se em produto de exportação para América Latina, Portugal e outros países da Europa. Possibilitou a concorrência entre todas as emissoras produtoras de telenovelas como: SBT, Record e Bandeirante.

\section{Telenovela enquanto espaço social e cultural}

A telenovela, que se tornou uma arte brasileira e popular, é um texto cultural que articula e produz emoção por meio da imagem televisiva. Entenderemos a noção de cultura e do espaço social como uma rede de significação dentro da trama da telenovela.

O que é cultura? Cultura é todo fazer humano que pode ser transmitido de geração a geração. A cultura é a soma de todas as realizações do homem.

Segundo Muniz Sodré (1989, p. 65), "cultura seria não apenas, um sistema de comportamento, mas também, o sistema da produção material ou o modo de produção econômico, pertinente a um grupo social".

A cultura está presente em nossas vidas, nas obras materiais, criadas pela técnica para o conforto e bem-estar do homem, como padrões comportamentais, normas, leis, valores, costumes, linguagens, modos de pensar, agir, religiões, etc. Pela aquisição de elementos da cultura, o homem se socializa, torna-se membro de uma determinada comunidade, consciente de seu papel.

A televisão é uma manifestação da cultura, com isso, traduz a ideia de nação em sentimento e cotidianidade. Tem a função de seduzir, agradar ao telespectador. Para 
Dominique Wolton (1996, p. 157), "a televisão é um fator de identidade cultural e de integração social, devido à dupla condição de ser uma televisão assistida por todas as classes sociais e de ser um espelho da identidade nacional".

Para Theodor Adorno (2002, p. 18),

o termo indústria cultural funciona como uma verdadeira indústria de produtos culturais, visando exclusivamente ao consumo. A indústria cultural vende mercadorias, mas, mais do que isso vende imagens do mundo e faz propaganda deste mundo tal qual ele é e para que ele assim permaneça. A indústria cultural pode fazer o que quer da individualidade somente porque nela, $e$ sempre, se reproduziu à íntima fratura da sociedade.

A televisão, enquanto indústria cultural, tem na telenovela seu principal bem da chamada cultura inserida em um contexto de mercado global. Portanto, a televisão se vincula no contexto social e cultural do brasileiro, participando ativamente no processo de construção de sua identidade individual $e$ social. É nesse sentido, apontado por Adorno, que tomamos aqui o conceito de indústria cultural quando nos referimos à programação televisiva, em especial, à telenovela como um produto dessa indústria.

A telenovela é um produto cultural, pois cria hábitos e costumes junto das pessoas e passa a ter um espaço diário em suas vidas, como forma de comunicação, de informação e entretenimento, nesse processo de democratização e nos países em desenvolvimento é o meio mais influente. Isso, também, está diretamente relacionado com essa geração, a das imagens.

Além de tudo isso, o que é, em verdade, um produto cultural? Se a telenovela reproduz uma realidade ou tenta reelaborá-la, e essa realidade corresponde, analogicamente, ao cotidiano brasileiro, então, ela pode ser considerada um produto cultural. A telenovela cria um determinado produto e o mostra como fruto de uma necessidade de um processo cultural, então ela não poderá escapar de ser considerada um instrumento de manipulação, à medida que, estipula padrões, até então, não utilizados anteriormente. Ao quebrar tabu, e os tabus são problemas complexos, pois normalmente envolvem sexualidade, racismo e outros, a telenovela impõe atitudes as quais, provavelmente, não seriam tomadas, se não fossem exibidas na tela da TV. Novamente, instrumentaliza-se para alienar, isto é, apressar, impor, manipular atitudes que se popularizam, devido ao alcance da televisão.

Para Maria Immacolata Lopes (2002, p. 52),

as telenovelas são os programas de maior audiência em toda a América Latina e sua importância cultural e política cresce continuamente porque deixam de ser apenas programas de lazer, e se tornam um espaço cultural de intervenção para a discussão $e$ a introdução de hábitos e valores.

A telenovela possibilita a abordagem de temas controversos, como homossexualismo e racismo, temas-tabus em qualquer sociedade, mas não escapa dos estereótipos e da criação de arquétipos, denotando tendenciosidade. Popularizar temas complexos, dentro de uma sociedade a qual não tem capacidade intelectual reflexiva, se torna perigoso ou no mínimo, não causará grandes efeitos a posteriori, pois o povo só se importa com o que está passando no momento. Depois do fim da telenovela, a tendência é o esquecimento, reflexo social comum, no Brasil, e tem a ver com a cultura do capitalismo. O consumo exagerado, não é algo regional, mas sim, mundial, com influências econômicas - ter e não ser.

$\mathrm{Na}$ verdade, a real validade das telenovelas deveria ser medida, depois de 
terminadas. Passado algum tempo, dever-seiam fazer levantamentos com a intenção de medir a continuidade do que foi questionado, durante o passar da telenovela. Se os resultados forem positivos, isto é, se o preconceito racial está diminuindo, ou se a discriminação aos homossexuais acabou, então, se atestaria o verdadeiro papel daquela telenovela, que tratou daquele tema. Ao contrário, se os resultados forem nulos, a telenovela não passou de simples entretenimento e moda passageira. Enquanto isso não acontece, as telenovelas brasileiras continuarão sendo um meio confortável de viver emoções como: alegria, frustração, ódio, vingança, paixão, etc, sentado na poltrona da sala, identificando-se com algum personagem e sonhando com a possibilidade da vida transformar-se tão rápida e maravilhosamente, como na telenovela das 21 horas.

A telenovela constitui sua dimensão estética e transitória sob a forma de uma prática cultural presente no cotidiano de cada um. O telespectador intercambia o sistema simbólico do folhetim como o mundo vivido, transformandoo em produto, espetáculo, mercadoria, aquilo que em seu contexto de ocorrência é o ponto culminante de um processo que parte do telespectador e a ele retorna, sendo indissociável em sua vida. Esse mundo vivido é expresso nos personagens, nas histórias, ou seja, um espaço de apreensão e conhecimento do imaginário coletivo.

A telenovela é o ponto de interação e intersecção entre o ator e o telespectador, dentro de um processo de retroalimentação de palavras, de sentimentos, de ações e reações e uma produção de significados, ela se integra no campo cultural, no cotidiano das pessoas em suas práticas culturais. Caracterizada como produto latino-americano, as telenovelas se espalharam por toda a América Latina com o advento da televisão. Os grandes produtores de telenovelas estão no México, Brasil e Venezuela. Não podemos esquecer que a Argentina, Chile e Colômbia, também as produzem.
Na América Latina, há consumidores cativos, um exemplo disto, sãos as audiências alcançadas pelas telenovelas brasileiras $e$ mexicanas. Sua penetração nas vidas das pessoas é incontestável, e, consequentemente, transformadora de suas realidades. A telenovela é um elo da realidade, ou seja, as realidades rurais e /ou urbana são apresentadas, como forma de cultura e identidade. Com isto, ela possui uma capacidade de promover discussão sobre tema social.

Para Michèle e Mattelart (1989, p. 30),

a identidade nacional não é uma teoria, mas uma prática do tempo livre. Devemos tudo ao melodrama. A catarse maciça $e$ as descargas emocionais que ele oferece a qualquer tipo de público organizam a compreensão da realidade. No melodrama se conjugam a impotência e a aspiração heróica de uma coletividade que não tem saídas públicas.

Os autores consideram a questão da identidade nacional, enquanto memória narrativa de um povo, no qual o melodrama apresentou no cinema, no teatro, no folhetim e na televisão, fortalecendo o lado emocional desse povo.

As mensagens veiculadas nas telenovelas criam um diálogo e consolidam crenças, comportamentos e estereótipos individuais e sociais, questionado nas pessoas uma semelhança entre o melodrama e a própria vida, a partir de uma identidade colocada nas cenas da telenovela. Em Laços de Família, de Manoel Carlos, exibida pela Rede Globo no horário das 21 horas em 2001, o autor relatou o sofrimento do personagem Camila (Carolina Dieckmann) em relação à doença de leucemia, provocando uma grande comoção no telespectador, e ao mesmo tempo, foi responsável por uma bem-sucedida campanha em favor da doação de medula. 
Nesse processo de identificação, o telespectador se reconhece no personagem com a doença, e há um sentido educativo para a população no tocante à prevenção ao câncer. Essa identificação, com a mensagem apresentada na telenovela, exige por parte do telespectador um reconhecimento de algo seu com a realidade, ou seja, uma realidade significativa com sua vida.

O real e o fictício são necessários para a condução da ação dramática, ou seja, a telenovela adquire um papel de transformar a realidade e o imaginário do telespectador. Por outro lado, ela estimula a discussão, a reflexão e a possível reelaboração dos discursos sociais já arraigados. A recepção em relação ao telespectador pode ocorrer tanto na projeção positiva ou negativa diante de personagem ou da estrutura da narrativa como um todo. Esse processo acontece em relação à comparação do telespectador com aquilo que lhe é próprio e significativo.

Depende muito como as temáticas sociais são conduzidas dentro da trama da telenovela pela conscientização do autor/diretor, da escolha do ator $e$ atriz que possuam uma imagem boa para o desenvolvimento da trama. Na telenovela América, de Glória Perez, exibida pela Rede Globo no horário das 21 horas em 2005, o personagem Jatobá (Marcos Frota) era um deficiente visual. $\mathrm{O}$ ator colocou tanta emoção no personagem que se tornou o ícone dos deficientes visuais.

Ainda Michèle e Mattelart (1989, p.76),

merchandising promove produtos de consumo, pode também promover serviços comunitários. Pode-se usá-lo, por exemplo, para ajudar a população a endereçar corretamente uma carta ou a adotar novos hábitos de higiene. Pode servir a finalidades ecológicas, como a preservação da flora e da fauna, ou fazer propaganda de instituições de interesse público.
Como a telenovela retrata situações do cotidiano, os autores estão colocando em suas tramas merchandising social, abrindo discussões sobre temas e situações em que o telespectador possa debater questões que vão desde a educação ambiental até prevenção da AIDS, passando por reforma agrária, homossexualismo, drogas e deficiências físicas.

Na telenovela Próxima Vítima, de Silvio de Abreu, exibida pela Rede Globo no horário das 21 horas em 1995, o autor utilizou a questão do preconceito racial, homossexualismo e drogas. Colocando os personagens nessas situações para dar credibilidade à telenovela em relação ao telespectador, o qual visualiza dentro um mundo parecido com o seu. Em História de Amor, de Manoel Carlos, exibida pela Rede Globo no horário das 18 horas em 1996, o autor mostrou através do personagem Assunção (Nuno Leal Maia), as desventuras de um deficiente físico e suas dificuldades pelas ruas da cidade do Rio de Janeiro e o preconceito enfrentado pelo deficiente físico em seu dia a dia. Em O Clone, de Glória Perez, exibida pela Rede Globo no horário das 21 horas em 2002 , a autora levantou a bandeira sobre drogas com o personagem Mel (Débora Falabella), e também inseriu nos capítulos depoimentos de viciados, alertando a população sobre o uso das drogas.

Em Senhora do Destino, de Aguinaldo Silva, exibida pela Rede Globo no horário das 21 horas em 2004, o autor trabalhou com delicadeza o lesbianismo dos personagens Jenifer (Bárbara Bruno) e Eleonora (Mylla Cristie). Magnífico esforço educativo para ensinar a população a conviver com as diferenças de gênero. A doença de Alzheimer, do personagem Baronesa de Bonsucesso (Glória Menezes), serviu como preciosa fonte de informação para o telespectador a respeito dessa doença que pode ser e deve ser tratada e não apenas considerada "coisa de velho" como acontecia até alguns anos, e ainda talvez aconteça junto das camadas da população com menor acesso à informação. A 
corrupção na política, mostrada por intermédio do personagem Reginaldo (Eduardo Moscovis), soou como mais um alerta para os nossos políticos e também para os eleitores. Em O Rei do Gado, de Benedito Ruy Barbosa, o autor inseriu na trama, o problema dos sem-terra $e$ da reforma agrária.

Ainda Sodré (1989, p.10),

todas essas campanhas são modos de avaliar a consciência dos sistemas discursivos das emissoras de televisão, quando elas chegam a um poder, como o que a Globo tem. É uma desculpa, pelo passado autoritário e pelo presente conivente.

Acreditamos que o merchandising social possa provocar discussão sobre seu uso dentro da telenovela, sobre qual seria sua contribuição para a sociedade. Com isso, os temas abordados, deverão ser muito bem elaborados pelos autores, para não caírem nos estereótipos, tendo em vista que a duração da telenovela é efêmera e estes assuntos só terão vida durante a exibição da mesma. O importante é trazer essa discussão para fora da narrativa, debatendo mesmo ao término da novela.

Martin Barbero (2001, p. 230), explica que os meios de comunicação não podem ser pensados como meros problemas de mercado e consumo, mas como um espaço decisivo, no qual é possível definir o público e construir a democracia. Para ele, é nesse empenho que os estudos culturais e os de comunicação dialogam uns com os outros.

A inter-relação que fazemos de tudo isso com a telenovela é de fácil compreensão. Hoje, o Brasil se transformou em produtor de bens simbólicos no contexto latino-americano, exportando telenovelas. As telenovelas brasileiras são exibidas no Japão, Rússia, China, Estados Unidos, Portugal e países da América Latina. Podem ser vistas em quase toda sua dimensão cultural, e com isso, os telespectadores dos mais longínquos países ganham em comunicação $e$ conhecimento. Assim, a mídia se transformou, até certo ponto, na grande mediadora e mediatizadora.

A exportação das telenovelas latinoamericanas representa uma afirmação da identidade de seu país de origem. Por exemplo, no México, a preocupação está no melodrama e com suas convenções para o tratamento das relações amorosas e sociais, abordando relevantes dados do contexto cultural do país.

Não consideramos meios de comunicação de massa apenas um instrumento limitador, mas entendemos que eles podem interagir nesse processo de renovações simbólicas e de afirmação, de identidades, de pessoas e de povos.

Ainda Michèle e Mattelart (1989, p.138),

a telenovela traz em si, dois objetivos fundamentais: o primeiro, em nível conjuntural, visa monopolizar a atenção do telespectador e o segundo, em nível estrutural, para atingir uma qualidade técnica cada vez mais apurada. Em relação ao primeiro ponto, afirmamos concretamente, que este faz parte da justificativa da existência da telenovela. Na verdade, este tipo de programa tem o seu público certo, que tradicionalmente acompanha todas as telenovelas ou a maioria delas, sejam elas boas (de grande aceitação popular) ou ruins (pouca ou nenhuma aceitação popular).

A qualidade de uma telenovela é dar consistência a dados estatísticos, que avaliem a popularidade da mesma. Terá uma relação, diretamente proporcional ao sucesso e o agrado do telespectador. Quanto mais bem aceita, maior será o sucesso da telenovela. Isso na verdade, não significa qual a qualidade como telenovela, como o que venha a ser uma telenovela representada, por essa relação proporcional. 
Essa medida qualitativa é extremamente relativa, pois o sucesso não é diretamente proporcional à qualidade técnica da telenovela. Isto nos conduz a dois pontos, os quais devem ser ressaltados: um deles, diz respeito ao conceito de qualidade em relação à aceitação popular, e o outro, em relação à forma técnica propriamente dia.

Outros critérios para avaliar a qualidade de uma telenovela, podem ser adotados, desde que sejam sempre baseados na reação do telespectador que a assiste, já que o objetivo principal, de quem realiza o trabalho é atingir o maior número de pessoas possíveis.

Em relação à estrutura da telenovela, ela é basicamente formada por: uma história consistente; a necessidade de existir uma busca, consciente ou não, de um determinado resultado. Isto é, deverá haver um suspense, adiado eternamente até o capítulo final, ou na melhor das hipóteses, deverão existir pequenos jogos, nos quais a verdade não revelada seja demonstrada em seguida, para que surjam outras pequenas verdades; um elenco de atores, com pelo menos uma empatia (de vilão ou de herói) com o telespectador; várias pequenas tramas e múltiplas personalidades, as quais compõem estruturalmente a telenovela, elas devem ser amarradas com extrema habilidade, para que não percam a consistência necessária, a fim de não tornar a trama insípida e sem interesse.

Analisando especificamente A Senhora do Destino, de Aguinaldo Silva, a telenovela visou monopolizar a atenção do telespectador no horário nobre. Afirmamos, concretamente, que esta é a própria justificativa da existência da telenovela. Na verdade, esse tipo de programa tem seu público certo, inercial até, que tradicionalmente acompanha todas as telenovelas, sejam boas ou más.

A trama da telenovela narrou a trajetória do personagem Maria do Carmo, interpretada pela atriz Susana Vieira, que ficou vinculada por conexões e relações com a própria existência real, dentro de um processo de passividade pessoal, individual e subjetivo do personagem, o qual projetou características gerais da alma humana e suas aflições, buscando identificação com os telespectadores. Aguinaldo Silva deixou de lado o realismo fantástico para escrever uma telenovela realista, cujo tema central é a luta de uma mulher nordestina para encontrar sua filha que foi sequestrada com poucos meses de vida. A história é dividida em duas fases, a primeira, ambientada em 1968 e relata a chegada de Maria do Carmo ao Rio de Janeiro, a segunda acontece nos anos 90. Em Senhora do Destino, os ambientes, os personagens e o enredo estavam em perfeita harmonia com o nosso dia a dia.

Nazaré (Renata Sorrah) representou o mal, ou seja, aquele tipo de gente que, para sobreviver, precisa levar vantagem, matar, corromper e roubar. Essa representação está presente no inconsciente coletivo, pois a agressividade de Nazaré é comum a todos nós, mas é reprimida, o que nos torna seres socializados. Assim, em cada cena em que aparecia esse personagem, foi aguçado nos telespectadores uma química provocando desejos reprimidos, gerando um interessante contraste de identificação e estranhamento que cativou o telespectador.

A discussão sobre a homossexualidade feminina entrou na trama com delicadeza, mas a intenção do autor era levantar discussões $e$ chamar a atenção para o preconceito e também para promover convívio harmonioso com as diferenças. O sentimento de nacionalismo também aflorou na telenovela. Os núcleos de personagem apresentaram diferentes extratos sociais do Brasil e com isto, o autor colocou na boca de seus personagens o slogan "Lugar de brasileiro é no Brasil", chamando a atenção dos telespectadores para uma conscientização de ser brasileiro e não ter vergonha de seu país, e sim, orgulho. A trama teve críticas sobre corrupção política, gravidez na adolescência, Mal de Alzheimer, violência doméstica. Essa 
combinação multitemática encaixou-se bem e atraiu a atenção do telespectador, despertandolhe questionamentos críticos em relação a esses problemas que compõem a pauta da atualidade.

A temática dessa telenovela teve como espinha dorsal à família colocada como referência de tudo e fortemente caracterizada em uma estrutura matriarcal. O personagem Giovanni (José Wilker) foi uma espécie de patriarca quixotesco, além de exercer o papel do masculino, do pai, representou, também, o elo com a comunidade, fortemente ligado aos seus desejos e desígnios. Aliás, José Wilker fez um bicheiro totalmente diferente, romântico, generoso e um ótimo pai. Um patriarca com contornos de caricatura sim, mas que exerceu sua função de líder.

A telenovela acompanha a dinâmica do momento pelo qual a sociedade vivencia, inserida no contexto dos membros de uma comunidade ou de uma sociedade. Com isto, ela se torna expressão de uma cultura, parte da identidade de um país.

\section{Telenovela e o processo educacional}

Ao considerar a telenovela um instrumento de educação, deve-se levar em consideração a especificidade desse fenômeno. Evidencia-se que sua especificidade se apresenta na sua forma de tratamento da mensagem, e não na mensagem propriamente dita. A telenovela deve ser considerada um produto da sociedade na qual se apresenta, por ser produzida por esta sociedade, ou seja, ela se revela como a sociedade se organiza e quais os seus valores e costumes. Nesta perspectiva, torna-se evidente que os educadores, de uma maneira geral, não promoveram estudos interdisciplinares com a telenovela.

Não é papel da indústria cultural promover a aproximação direta entre os estudantes e suas obras. É uma atitude que cabe ao sistema educacional e à família, embora isso não impeça a televisão de participar do processo educativo. A televisão manipula o telespectador porque é a única que detém a informação e a tecnologia, mas na medida em que a sociedade interage, toma esse poder para si, determina o que quer, como quer, passa a construir o dia a dia, a cultura, o melhor, as mazelas da vida. Isso quer dizer que o telespectador passará a compreender que ele pode melhorar a vida, ir além da ficção, que as mudanças são possíveis, tanto no campo pessoal quanto social.

Há, nessaperspectiva, umaaproximação entre o real e o imaginário. Tradicionalmente, os brasileiros têm maior identidade com a comunicação oral e visual, consequência dos longos processos de alfabetização, da falta de estímulo à leitura, e até mesmo do modo como foi a história de nossa colonização.

Segundo Ciro Marcondes Filho (1996, p.34),

a imagem é uma ponte de ligação entre o homem e seu imaginário. Imaginário é uma dimensão que existe no homem, paralelamente à dimensão do real. $\mathrm{O}$ real é a atividade produtiva, o trabalho que gera alimentos, mercadorias, meios de transportes, educação. O imaginário é social, coletivo, e a forma como se organiza é por meio de símbolos. E a televisão é a forma eletrônica mais desenvolvida de dinamizar esse imaginário. É, também, a maior produtora de imagens.

Por meio dos apelos das telenovelas - referimo-nos aos apelos visuais e recursos tecnológicos - o educador poderá ver e sentir um maior interesse por parte dos estudantes. Estes sentem prazer com esse tipo de proposta - a interação entre telenovela e conteúdos - que lhes chegam de uma maneira muito mais familiar, de modo a sentirem muito conforto em olhar para os 
novos conhecimentos por meio desses filtros, que lhes são tão seguros. As mudanças, então, virão de uma forma suave $e$ inteligente. O professor deverá estimular a crítica, sem agressividade, como parte do processo espontâneo da vida.

Os professores dedicam parte de seu tempo na sala de aula para chamar a atenção dos alunos, pedindo silêncio, implorando para que os alunos prestem atenção no que têm a dizer. Os tempos mudaram e as linguagens também. Assim, a comunicação em sala de aula precisa ser aperfeiçoada. Os jovens, atualmente, estão muito mais voltados e familiarizados com os recursos tecnológicos, isso já está incorporado em sua linguagem.

O discurso pedagógico deve considerar atelenovelaum diálogo crítico, e ao mesmotempo, reconhecendo as possibilidades operacionais que abre para a escola um aprendizado sobre esse gênero televisivo. A telenovela é considerada um discurso não escolar, mas não podemos esquecer que ela tem presença na vida dos estudantes $e$ dos professores. Passa despercebida do discurso pedagógico, por insegurança dos professores em se aventurarem em trabalhá-la em sala de aula.

A telenovela como discurso pedagógico é um grande desafio para a educação, pois possui história que se multiplica em trama principal e subtramas, personagens vivendo conflitos, problemas e romances. Ela é importante, pois introduz temas que servem de gancho para tratarmos de assuntos que nos incomodam e não temos coragem de falar. Esse diálogo deve ser construído pelos professores por meio de objeto de análise e crítica dentro da sala de aula sem medo e sem preconceitos.

\section{Considerações finais}

A telenovela é um meio de comunicação, um elemento de influência para a avaliação da história e dos personagens. Também projeta no telespectador a fantasia e o imaginário. A linguagem da telenovela é simples, despojada, concreta, possibilitando ao telespectador acompanhá-la sem maior esforço de entendimento. O ritmo é acelerado, baseia-se na ação, por isso a telenovela é uma narrativa de ação. Constitui-se, assim, uma ferramenta da educação, ou melhor, pode contribuir nas construções de valores e de autoconhecimento $e$ na aprendizagem por meio de uma investigação $e$ crítica no sentido de como são desenvolvidas.

O professor não é o vilão dessa história, é tão vítima quanto os alunos. Não tendo o devido preparo em seus cursos de graduação e licenciatura, o professor não se aventura a trabalhar com a teledramaturgia em sala de aula, especialmente porque não domina essa linguagem, mas esse quadro pode ser mudado, ou seja, se o estudo da linguagem da telenovela for incluído nos planos de aula do ensino fundamental e médio, será bem aproveitado, de forma interdisciplinar, em algumas disciplinas, tais como: Língua Portuguesa, Geografia, História, Educação Artística, Sociologia, Filosofia, etc.

Assim como a sociedade, pais, direção e professores, a escola também exclui a telenovela, considerando-a um produto aquém e desprezando-a. A realidade é que o educador não sabe o que e como explorar dentro deste gênero, não percebe que a telenovela é um rico instrumento de apoio aos conteúdos interdisciplinares.

O estudante brasileiro, em grande maioria, vem da cultura da oralidade, e nós sabemos da dificuldade de acesso a livros, jornais, etc. Dessa forma, não podemos deixar a telenovela fora do contexto da escola, pois ela está nas discussões dos estudantes, dos professores e do povo em geral, é fundamental que haja um debate mais abrangente em sala de aula.

Precisamos interagir com os meios de comunicação, principalmente a telenovela em 
relação ao gênero literário. Mas o preconceito ainda é grande. Precisamos dar partida para que isso seja disseminado do nosso ensino, assim, estaremos diversificando a qualidade e também possibilitando aos nossos estudantes ampliarem a visão crítica em relação às discussões levantadas no cotidiano das telenovelas, traçando paralelos com a vida real.

\section{REFERÊNCIAS}

ADORNO, Theodor. Indústria cultural e sociedade. Rio de Janeiro: Paz e Terra, 2002.

ALVAREZ, Sônia, E. (Org). Cultura e política nos movimentos sociais latino-americanos. Belo Horizonte: UFMG, 2000.

ANDRADE, B. M. Roberta, O fascínio de Scherazade: os usos sociais da telenovela. São Paulo: Annablume, 2003.

BALOGH, Maria Ana. O discurso ficcional na TV. São Paulo: Edusp, 2002.

BARBERO, Martin Jesús. Dos meios às mediações: comunicação, cultura e hegemonia. Rio de Janeiro: UFRJ, 2001.

BRAIT, Beth. A personagem. 3. ed. São Paulo: Ática, 1987.

BRANDEN, Nathaniel. A psicologia do amor romântico. Rio de Janeiro: Imago, 1982.

BRÉMOND, Claude. Literatura e semiologia. Petrópolis: Vozes, 1972.

CALZA, Rose. O que ételenovela. São Paulo: Brasiliense, 1994.

CANCLINI, Néstor García. Culturas híbridas: estratégias para entrar e sair da modernidade. São Paulo: Edusp, 1997.

Consumidores e cidadãos: conflitos multiculturais da globalização. Rio de Janeiro: UFRJ, 2001.

COMPARATO, Doc. Roteiro: arte e técnica de escrever para cinema e televisão. Rio de Janeiro: Nórdica, 1983.

CÂNDIDO, Antônio. A personagem de ficção. São Paulo: Perspectiva, 1968.

COSTA, Cristiane. Eu compro essa mulher: romance e consumo nas telenovelas brasileiras e mexicanas. Rio de Janeiro: Zahar, 2000.

COSTA, Freire Jurandir. Sem fraude nem favor: estudos sobre o amor romântico. Rio de Janeiro: Rocco, 1998.
Se a telenovela é aceita e amplamente difundida entre o convívio social, logo ela pode permear todo o trabalho educacional. A escola já não pode ignorar a importância e o impacto dessa produção cultural como meio transformador da vida dos jovens e de nossa sociedade.

FEIJÓ, Cezar Martin. O que é herói. São Paulo: Brasiliense, 1984.

FERNANDEZ, Ismael. Memória da telenovela brasileira. São Paulo: Brasileira, 1994.

FIGUEIREDO, Ana Maria C. Teledramaturgia brasileira: arte ou espetáculo. São Paulo: Paulus, 2003.

FILHO, Marcondes Ciro. Televisão: a vida pelo vídeo. 13. ed. São Paulo: Moderna, 1996.

FORSTER, E. M. Aspectos do romance. Porto Alegre: Globo, 1970.

GARCÍA, Pedro Gómez. La Antropología estructural de Claude Lévi-Strauss. Madrid: Tecnos, 1981.

GOMEZ, Guilhermo Orozco. Televidencia. Perspectiva para el analise de los procesos de recepción televisiva. México: Universidad Iberoamericana, 1994.

GANCHO, Cândida Vilares. Como analisar narrativas. São Paulo: Ática, 1999.

GOTLIB, Battella Nádia. Teoria do conto. 4. ed.São Paulo: Ática, 1998.

GREIMAS, A. J. Semântica estrutural. São Paulo: Cultrix, 1973.

HUPPES, Ivete. Melodrama - o gênero e sua permanência. São Paulo: Ateliê, 2000.

LOPES, Maria Immacolata V.; BORELLI, Silvia Helena S. Vivendo com a telenovela: mediações, recepção, teleficcionalidade. São Paulo: Summus editorial, 2002.

MATTELART, Michéle e Armand. O carnaval das imagens: a ficção na TV. São Paulo: Brasiliense, 1989.

MESQUITA, Nahid Samira. O enredo. 2. ed. São Paulo: Ática, 1987.

MEYER, Marlyse. Folhetim: uma história. São Paulo: Companhia das Letras, 1996.

MOISÉS, Massaud. A criação literária. São Paulo: Cultrix, 1978. 
MORAN, Manuel José. Leituras dos meios de comunicação. São Paulo: Pancast, 1993.

MOTTER, Lourdes Maria. Fiç̧ão e realidade: a construção do cotidiano na telenovela. São Paulo: Alexa Cultural, 2003.

OROZ, Silvia. Melodrama: o cinema de lágrimas da América Latina. Rio de Janeiro: Rio Fundo Editora, 1999.

PALLOTTINI, Renata. Dramaturgia de televisão. São Paulo: Moderna, 1998.

PAVIS, Patrice. Dicionário de teatro. São Paulo: Perspectiva, 1999.

PLATÃO. O banquete. 2. ed. São Paulo: Difel, 1970.

PROPP, Vladimir. Morfologia do conto. Lisboa: Editorial Vega, 1978.
. As raízes históricas do conto maravilhoso. 2. ed. São Paulo: Martins Fontes, 2002.

ROUGEMONT, Denis. História do amor no ocidente. 2. ed. São Paulo: Ediouro, 2003.

SANTAELLA, Lúcia. Matrizes da linguagem e pensamento. São Paulo: Iluminuras, 2001.

SODRÉ, MUNIZ. O monopólio da fala. 5. ed. Petrópolis. Vozes, 1989.

STRAUSS, Lévi Claude. Antropologia estrutural. Rio de Janeiro: Edições Tempo Brasileiro, 1973.

TÁVOLA, Artur da. A telenovela brasileira: história, análise e conteúdo. São Paulo: Globo, 1996.

WOLTON, Dominique. O elogio ao grande público. São Paulo: Ática, 1996.

Texto recebido em 2 de janeiro de 2009. Texto aprovado em 6 de fevereiro de 2009. 